\title{
Improved DTC Control Strategy of B12 Inverter Fed BLDC Motor Drives Considering Commutation Torque Dips
}

\author{
Rabiaa Mars $\Psi^{\Uparrow}$, Badii Bouzidi, Bassem El Badsi, Abderrazak Yangui \\ University of Sfax, Electrical Department, Sfax Engineering National School, P.O. Box 1173, 3038 Sfax, Tunisia
}

A R T I C L E I N F O
Article history:
Received: 10 July, 2018
Accepted: 09 October, 2018
Online: 24 October, 2018
Keywords:
Brushless DC motor
Commutation torque dips
Direct torque control scheme
Current slope
Simulation results

\section{Introduction}

The use of three-level NPC (B12) inverter in highpower applications increases due to their performances [1]- [2]. Indeed, compared to the two-level inverter, the B12 inverter offers the low output current distortion and operates with reduced $\mathrm{dv} / \mathrm{dt}$ stress [3][4]-[5]-6].

Due to its numerous advantages as its simple structure, low noise, good stability and high efficiency [7]-[8]-9], BLDC motor is extensively used in numerous industrial applications. Conversely, the torque ripple is a critical issue in BLDC motor drives [10][11]-[12]. Accordingly, minimizing the ripple produced in the torque is necessary to enhance the performances of BLDC motor drive system [13]-[14].

The present paper proposes two DTC strategies dedicated to the BLDC motor fed by three-level (B12) inverter. It has been found that commutation torque ripple is a main problem penalizing the first proposed strategy. This commutation phenomenon af- fects the industrial applications needing high performance [15]-[16]. It leads to a deteriorating efficiency of the BLCD motor. Hence, the second proposed strategy aims to address these drawbacks.

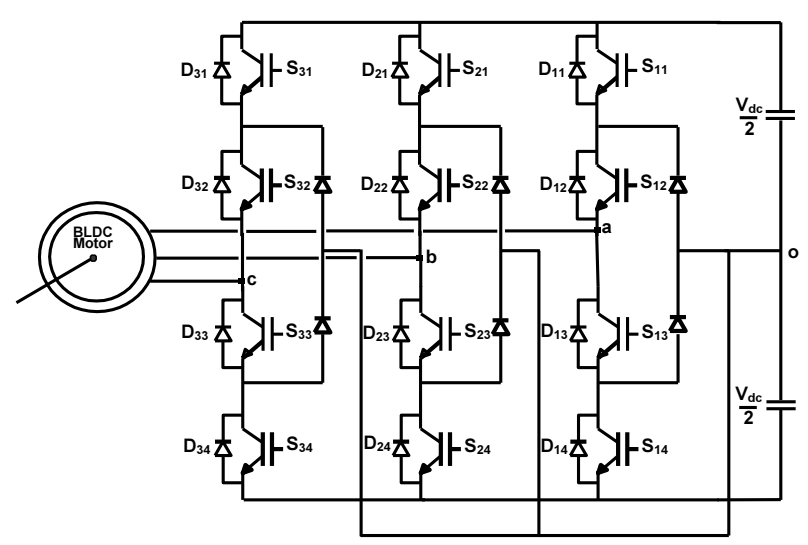

Figure 1: B12 inverter with BLDC motor connected.

* Rabiaa Mars, Sfax Engineering National School, marsrabiaa@yahoo.com 


\section{Analysis of the BLDC motor operation}

The B12 inverter is connected with BLDC motor as illustrated in Figure 1

The rectangularly shaped currents $\left(i_{a}, i_{b}, i_{c}\right)$ fed BLDC motor are synchronized with the trapezoidal back-EMFs $\left(\mathrm{e}_{a}, \mathrm{e}_{b}, \mathrm{e}_{c}\right)$ to accomplish a constant torque with reduced dips as shown in Figure.2.

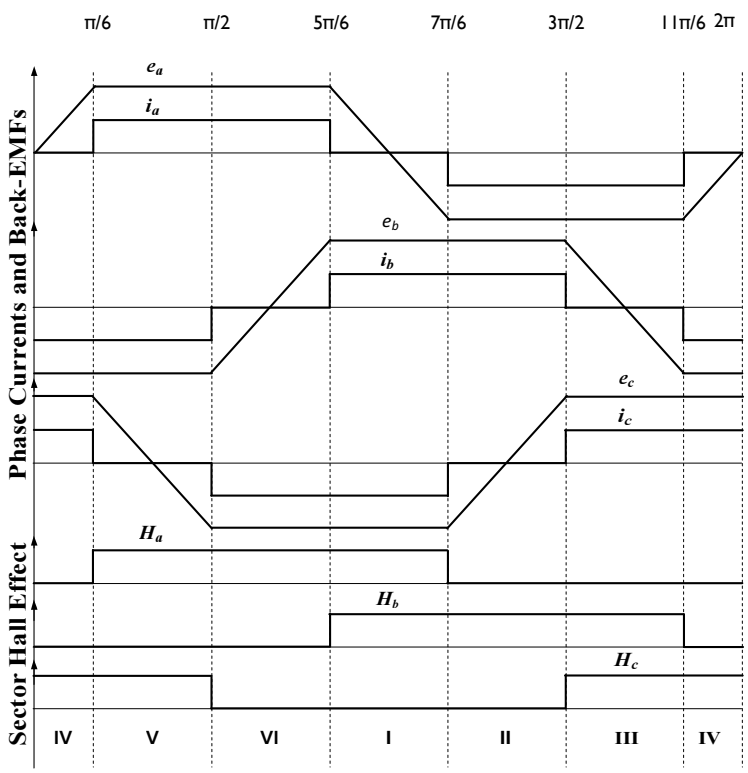

Figure 2: Back-EMFs, phase currents and the corresponding Hall-effect signals of BLDC motor .

The BLDC motor stator voltages $\left(\mathrm{v}_{a}, \mathrm{v}_{b}, \mathrm{v}_{c}\right)$ are given by:

$$
\left\{\begin{array}{l}
v_{a}=\mathrm{Ri}_{a}+(\mathrm{L}-\mathrm{M}) \frac{d i_{a}}{d t}+\mathrm{e}_{a} \\
v_{b}=\mathrm{Ri}_{b}+(\mathrm{L}-\mathrm{M}) \frac{d i_{b}}{d t}+\mathrm{e}_{b} \\
v_{c}=\mathrm{Ri}_{c}+(\mathrm{L}-\mathrm{M}) \frac{d i_{c}}{d t}+\mathrm{e}_{c}
\end{array}\right.
$$

Where:

- Resistance: $\mathrm{R}(\Omega)$,

- Self inductance: $\mathrm{L}(\mathrm{H})$,

- Mutual inductance: $\mathrm{M}(\mathrm{H})$.

The produced torque $\mathrm{T}_{e m}$ is given as:

$$
T_{e m}=\frac{e_{a} i_{a}+e_{b} i_{b}+e_{c} i_{c}}{\Omega}
$$

Where $\Omega$ represents the angular speed.

Under two-phase conduction mode, the B12 inverter engenders six Half voltage vectors $\left(\mathrm{V}_{1}\right.$ to $\left.\mathrm{V}_{6}\right)$ and six Intermediate Voltage Vectors $\left(\mathrm{V}_{7}\right.$ to $\left.\mathrm{V}_{12}\right)$.

Under three-phase conduction mode, the B12 inverter generates three null vectors $\left(U_{01}\right.$ to $\left.U_{03}\right)$, six
Intermediate voltage vectors $\left(\mathrm{U}_{1}\right.$ to $\left.\mathrm{U}_{6}\right)$ and six Full Voltage Vectors $\left(\mathrm{U}_{7}\right.$ to $\left.\mathrm{U}_{12}\right)$.

Tables 1 and 2 provide the switch state combinations.

Table 1: Active voltage vectors under the two-phase conduction mode.

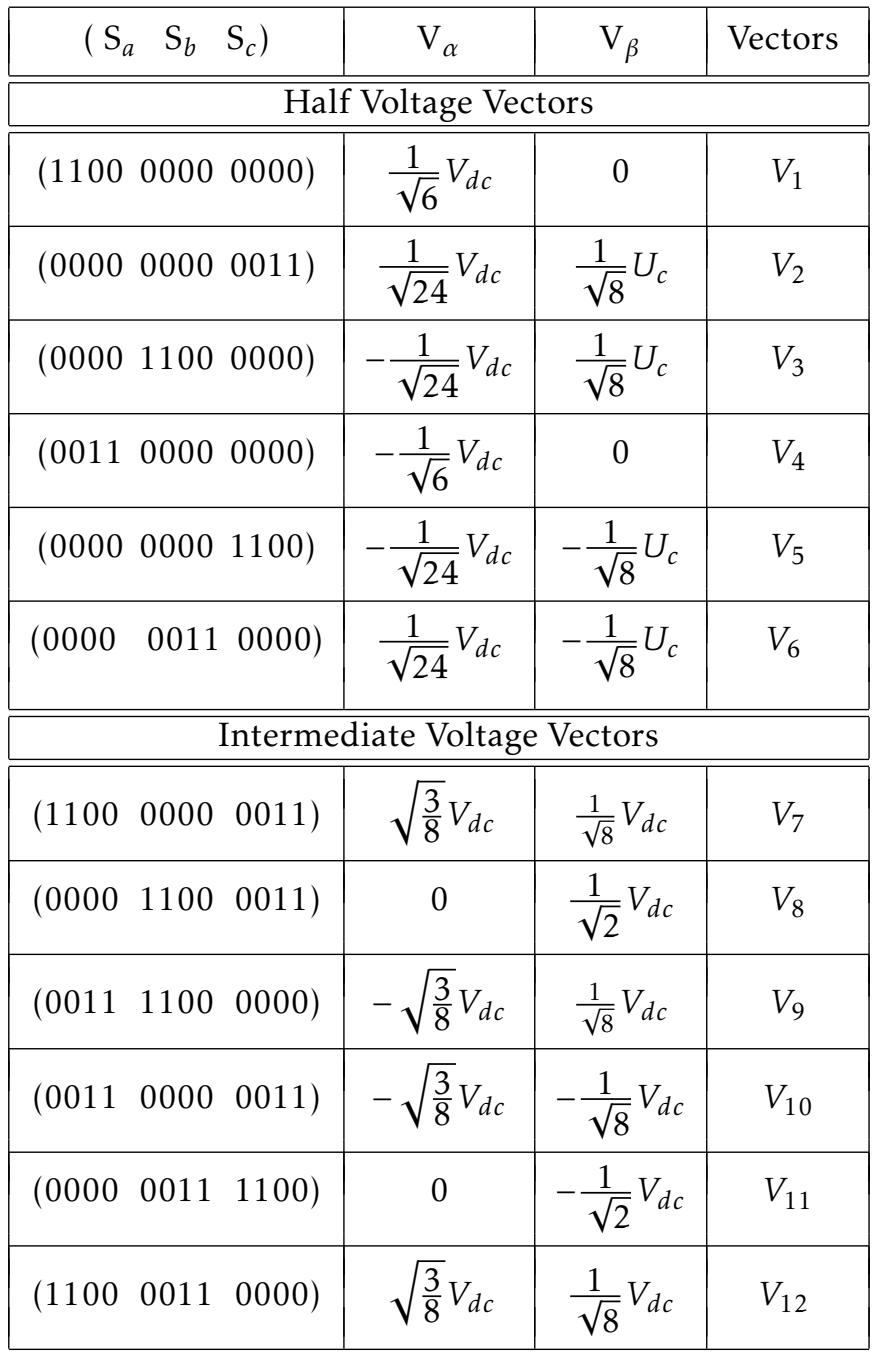

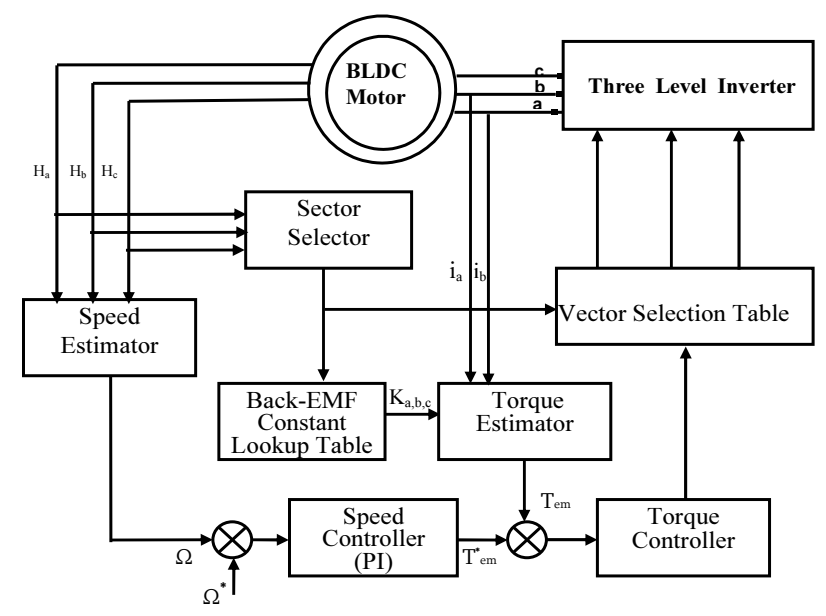

Figure 3: DTC scheme of the B12 inverter with BLDC motor connected. 


\section{Control strategies}

\subsection{DTC-1 strategy}

The DTC-1 scheme is inspired from the one proposed by Takahashi in [17]. This strategy allows a direct control of the BLDC motor torque.

The DTC-1 scheme block diagram is illustrated in Figure.3. This diagram includes an hysteresis torque estimator which generates two outputs used to determine the vector selection table $\left(c_{\tau}=+1\right.$ :torque increase, $c_{\tau}=-1$ :torque decrease).

The switching table of this strategy is summarized in Table 3 .

Table 2: Active voltage vectors under the three-phase conduction mode.

\begin{tabular}{|c|c|c|c|}
\hline$\left(\begin{array}{lll}S_{a} & S_{b} & S_{c}\end{array}\right)$ & $\mathrm{V}_{\alpha}$ & $\mathrm{V}_{\beta}$ & Vectors \\
\hline \multicolumn{4}{|c|}{ Intermediate Voltage Vectors } \\
\hline$\left(\begin{array}{lll}1100 & 0010 & 0011\end{array}\right)$ & $\sqrt{\frac{3}{8}} V_{d c}$ & $\frac{1}{\sqrt{8}} V_{d c}$ & $\mathrm{U}_{1}$ \\
\hline$\left(\begin{array}{lll}0100 & 1100 & 0011\end{array}\right)$ & 0 & $\frac{1}{\sqrt{2}} V_{d c}$ & $\mathrm{U}_{2}$ \\
\hline$\left(\begin{array}{lll}0011 & 1100 & 0010\end{array}\right)$ & $-\sqrt{\frac{3}{8}} V_{d c}$ & $\frac{1}{\sqrt{8}} V_{d c}$ & $\mathrm{U}_{3}$ \\
\hline$\left(\begin{array}{lll}0011 & 0100 & 0011\end{array}\right)$ & $-\sqrt{\frac{3}{8}} V_{d c}$ & $-\frac{1}{\sqrt{8}} V_{d c}$ & $\mathrm{U}_{4}$ \\
\hline$\left(\begin{array}{lll}0010 & 0011 & 1100\end{array}\right)$ & 0 & $-\frac{1}{\sqrt{2}} V_{d c}$ & $\mathrm{U}_{5}$ \\
\hline$\left(\begin{array}{lll}1100 & 0011 & 0100\end{array}\right)$ & $\sqrt{\frac{3}{8}} V_{d c}$ & $U 6$ & \\
\hline \multicolumn{4}{|c|}{ Full Voltage Vectors } \\
\hline$\left(\begin{array}{lll}1100 & 0011 & 0011\end{array}\right)$ & $\sqrt{\frac{2}{3}} V_{d c}$ & 0 & $U_{7}$ \\
\hline$\left(\begin{array}{lll}1100 & 1100 & 0011\end{array}\right)$ & $\frac{1}{\sqrt{6}} V_{d c}$ & $\frac{1}{\sqrt{2}} V_{d c}$ & $U_{8}$ \\
\hline$\left(\begin{array}{lll}0011 & 1100 & 0011\end{array}\right)$ & $-\frac{1}{\sqrt{6}} V_{d c}$ & $\frac{1}{\sqrt{2}} V_{d c}$ & $U_{9}$ \\
\hline$\left(\begin{array}{lll}0011 & 1100 & 1100\end{array}\right)$ & $-\sqrt{\frac{2}{3}} V_{d c}$ & 0 & $U_{10}$ \\
\hline$\left(\begin{array}{lll}0011 & 0011 & 1100\end{array}\right)$ & $-\frac{1}{\sqrt{6}} V_{d c}$ & $-\frac{1}{\sqrt{2}} V_{d c}$ & $U_{11}$ \\
\hline$\left(\begin{array}{lll}1100 & 0011 & 1100\end{array}\right)$ & $\frac{1}{\sqrt{6}} V_{d c}$ & $-\frac{1}{\sqrt{2}} V_{d c}$ & $U_{12}$ \\
\hline
\end{tabular}

\subsection{DTC-2 strategy}

It has been found that DTC-1 scheme is penalized by the high torque dips. In view of that, the DTC-2 is proposed to address the DTC- 1 limitations. The control scheme of this strategy is similar to the one used in the DTC-1. The only difference is the control rules considered in the vector selection table.
Table 3: The DTC-1 strategy vector selection table.

\begin{tabular}{|c|c|c|}
\hline$c_{\tau}$ & +1 & -1 \\
\hline \hline Sector I & $\mathbf{V}_{8}(000011000011)$ & $\mathbf{V}_{11}(000000111100)$ \\
\hline Sector II & $\mathbf{V}_{9}(001111000000)$ & $\mathbf{V}_{12}(110000110000)$ \\
\hline Sector III & $\mathbf{V}_{10}(001100000011)$ & $\mathbf{V}_{7}(110000000011)$ \\
\hline Sector IV & $\mathbf{V}_{11}(000000111100)$ & $\mathbf{V}_{8}(000011000011)$ \\
\hline Sector V & $\mathbf{V}_{12}(110000110000)$ & $\mathbf{V}_{9}(001111000000)$ \\
\hline Sector VI & $\mathbf{V}_{7}(110000000011)$ & $\mathbf{V}_{10}(001100000011)$ \\
\hline
\end{tabular}

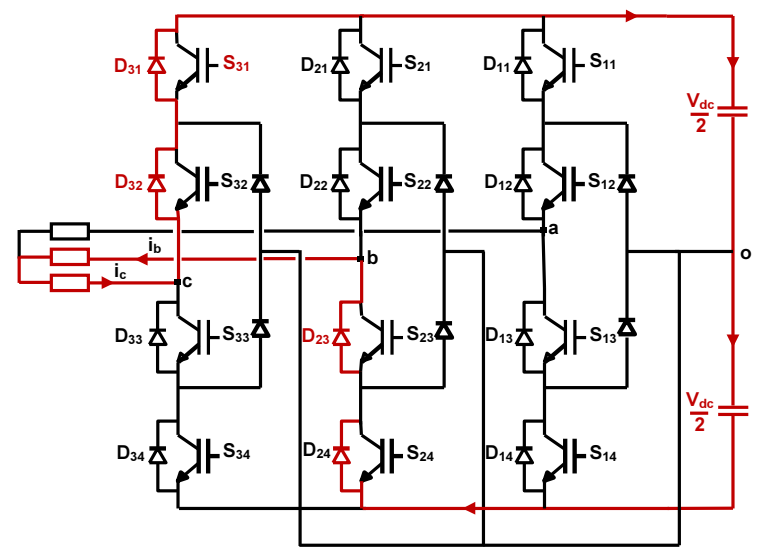

(a)

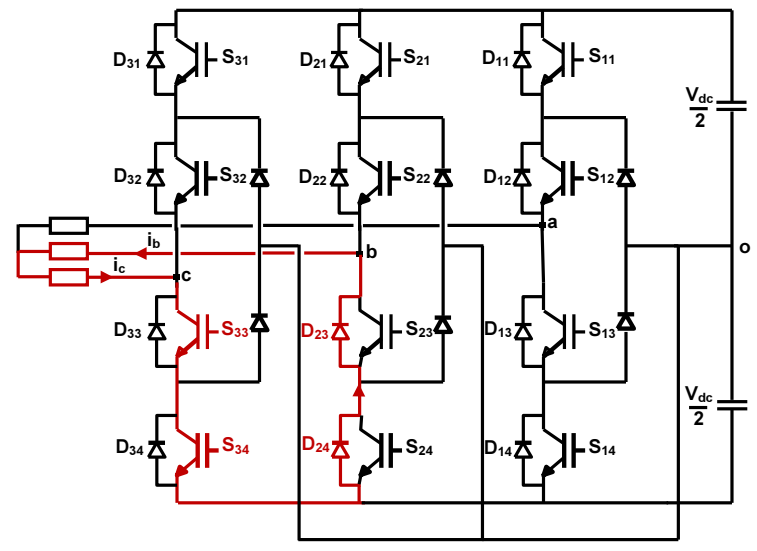

(b)

Figure 4: The current flowing during sector I in the case of a torque decrease under Legend (a): the DTC1 scheme, (b): the proposed DTC-2 scheme.

Let's consider sector I, the vector selection table design of this scheme is synthesized as follows:

- To increase the torque, the DTC-2 scheme considers the same vectors applied in DTC-1,

- the vector $\mathrm{V}_{2}$ achieves the torque decrease. As 
illustrated in Figure. $4(\mathrm{~b})$, the vector $\mathrm{V}_{2}$ is defined by a freewheeling phase involving the two IGBTs $\mathrm{S}_{33}$ and $\mathrm{S}_{34}$ and the diodes $\mathrm{D}_{23}$ and $\mathrm{D}_{24}$. Compared to DTC-2, the DTC-1 scheme considers the vector $\mathrm{V}_{8}$ which characterized by a regenerative phase. During this phase, the currents $i_{c}$ and $i_{b}$ are forced to flow through the supply source $\mathrm{Vdc}$ and the diodes $\left(\mathrm{D}_{23}, \mathrm{D}_{24}, \mathrm{D}_{31}\right.$ and $\mathrm{D}_{32}$ ) as shown in Figure. $4(\mathrm{a})$. The currents slope observed under this phase has an absolute value higher than the one obtained under the freewheeling phase.

Consequently, the resulting DTC-2 strategy vector selection table is given in Table 4

Table 4: The DTC-2 strategy vector selection table.

\begin{tabular}{|c|c|c|}
\hline$c_{\tau}$ & +1 & -1 \\
\hline \hline Sector I & $\mathbf{V}_{8}(000011000011)$ & $\mathbf{V}_{2}(000000000011)$ \\
\hline Sector II & $\mathbf{V}_{9}(001111000000)$ & $\mathbf{V}_{3}(000011000000)$ \\
\hline Sector III & $\mathbf{V}_{10}(001100000011)$ & $\mathbf{V}_{4}(001100000000)$ \\
\hline Sector IV & $\mathbf{V}_{11}(000000111100)$ & $\mathbf{V}_{5}(000000001100)$ \\
\hline Sector V & $\mathbf{V}_{12}(110000110000)$ & $\mathbf{V}_{6}(000000110000)$ \\
\hline Sector VI & $\mathbf{V}_{7}(110000000011)$ & $\mathbf{V}_{1}(110000000000)$ \\
\hline
\end{tabular}

\subsection{DTC-3 strategy}

It has been found that DTC-2 scheme is penalized by the commutation torque ripple. As illustrated in Figure $5(\mathrm{a})$, the difference between the slopes of the incoming and outgoing phases currents generates commutation torque dips. In view of that, there is a necessity to make equal the rising time and the falling one of the phase currents as illustrated in Figure.5(b).

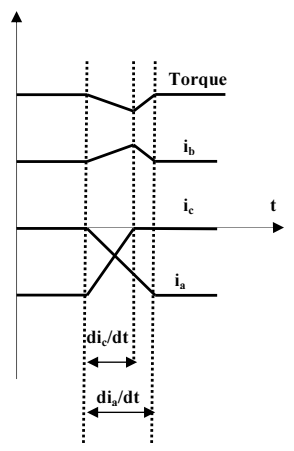

(a)

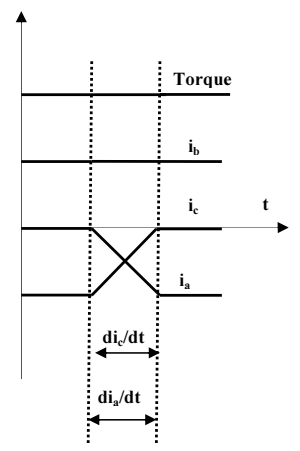

(b)
Figure 5: The behavior of the torque during commutation Legend (a): unequal slopes of the incoming and outgoing phases currents, (b): equal slopes of the incoming and outgoing phases currents.
The stator voltage equations of the BLDC motor are described by the equation (1). Neglecting the mutual inductance, $\mathrm{v}_{a}, \mathrm{v}_{b}$ and $\mathrm{v}_{c}$ are given by the following system :

$$
\left\{\begin{array}{l}
v_{a}-e_{a}=\mathrm{Ri}_{a}+\mathrm{L} \frac{d i_{a}}{d t} ; \\
v_{b}-e_{b}=\mathrm{Ri}_{b}+\mathrm{L} \frac{d i_{b}}{d t} ; \\
v_{c}-e_{c}=\mathrm{Ri}_{c}+\mathrm{L} \frac{d i_{c}}{d t} .
\end{array}\right.
$$

The Laplace Transform method can be used to solve this linear differential equations. Therefore the relation between the phase voltage and the phase current is dealt with using this method, and then the transfer function is similarly written as:

$$
H(p)=\frac{v(p)-e(p)}{i(p)}=\frac{1}{L p-R}
$$

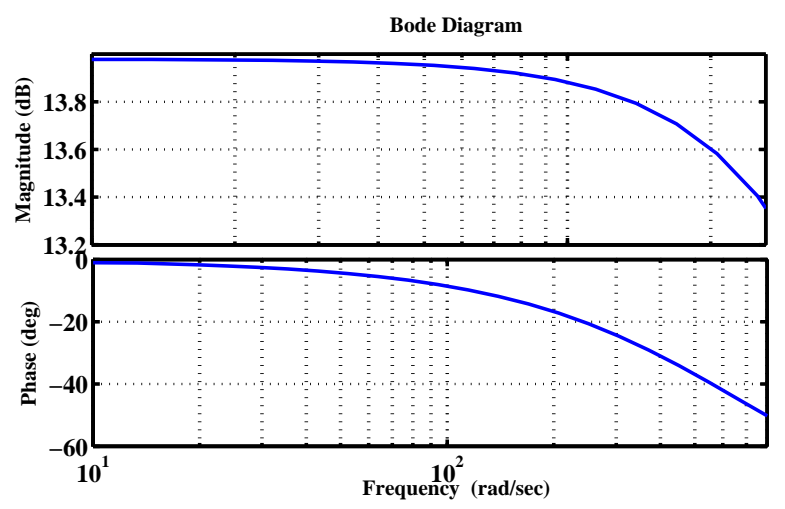

Figure 6: Approximated curve of the frequency response (bode-plot) of the BLDC motor.

Figure6 shows the approximated curve of the frequency response (bode-plot) based on equation (4). The plot displays the magnitude (in $\mathrm{dB}$ ) and the phase (in degrees) of the system response as a function of frequency. Referring to this figure, the phase delay angle increases with the increase of the rotation speed. Moreover, this delay is more important at high speed. Consequently, the commutation torque dips is very serious at high speed.

To address the DTC-2 limitations, the third DTC scheme, noted DTC-3, is proposed. This strategy is based on the employ of a three-level torque controller. This controller generates 3 outputs as shown in Figure 7:

- -1 corresponding to the torque decrease,

- +1 corresponding to the torque increase,

- +2 is activated when the torque drops during commutations from sector-to-sector . 


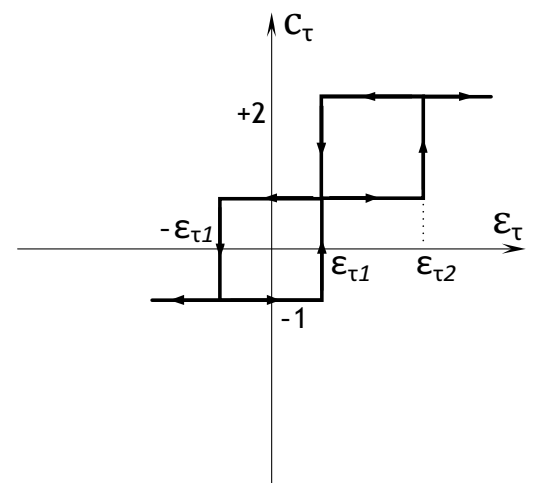

Figure 7: The three-level-torque controller characteristics.

Let's consider sector I, the vector selection table design of this scheme is synthesized as follows:

- $c_{\tau}=+1$ and $c_{\tau}=-1$ are achieved by the same vectors used in DTC-2 scheme.

- The suppression of the commutation torque dips $\left(c_{\tau}=+2\right)$ is achieved by the application of the vectors corresponding to the three-phase conduction mode. To equalize $\left|d i_{a} / d t\right|$ and $\left|d i_{c} / d t\right|$, at the beginning of sector II, in the case of a reference speed $\Omega^{*} \leq \Omega_{\text {limit }}$, the current $i_{c}$ is forced to flow through the IGBT $S_{33}$, the clamped diode and the supply source $\frac{V_{d c}}{2}$ instead of the uncontrollable diodes $\left(D_{31}\right.$ and $\mathrm{D}_{32}$ ) as shown in Figures. 8(b) and 8(c). For a reference speed $\Omega>\Omega_{\text {limit }}$, the current $\mathrm{i}_{c}$ is forced to flow through the IGBTs $\left(\mathrm{S}_{33}, \mathrm{~S}_{34}\right)$ and the supply source $\mathrm{V}_{d c}$ instead of the uncontrollable diodes $\left(\mathrm{D}_{31}\right.$ and $\left.\mathrm{D}_{32}\right)$ as shown in Figures. 8(b) and 8(d).

Consequently,the resulting vector selection is given in Table 7.

\section{Evaluation of the proposed DTC schemes effectiveness and per- formances}

Simulation work has been accomplished to highlight the proposed strategies performances. Tables 5 and 6 gives the BLDC motor parameters and ratings.

Table 5: The ratings of BLDC motor

\begin{tabular}{|l||l|}
\hline Current $=30 \mathrm{~A}$ & DC voltage $=24 \mathrm{~V}$ \\
\hline Rated torque $=2.5 \mathrm{Nm}$ & PM flux-linkage $=14 \mathrm{mWb}$ \\
\hline Power $=600 \mathrm{~W}$ & Rated speed $=2500 \mathrm{rpm}$ \\
\hline
\end{tabular}

Table 6: BLDC motor parameters

\begin{tabular}{|c||l|}
\hline$R=0.2 \Omega$ & $p=3$ \\
\hline$L=0.3 \mathrm{mH}$ & $J=4.1 \mathrm{~g} \cdot \mathrm{m}^{2}$ \\
\hline $\mathrm{R}=0.2 \Omega$ & $\mathrm{f}=0.5 \mathrm{mN} . \mathrm{m} . \mathrm{s}$ \\
\hline
\end{tabular}

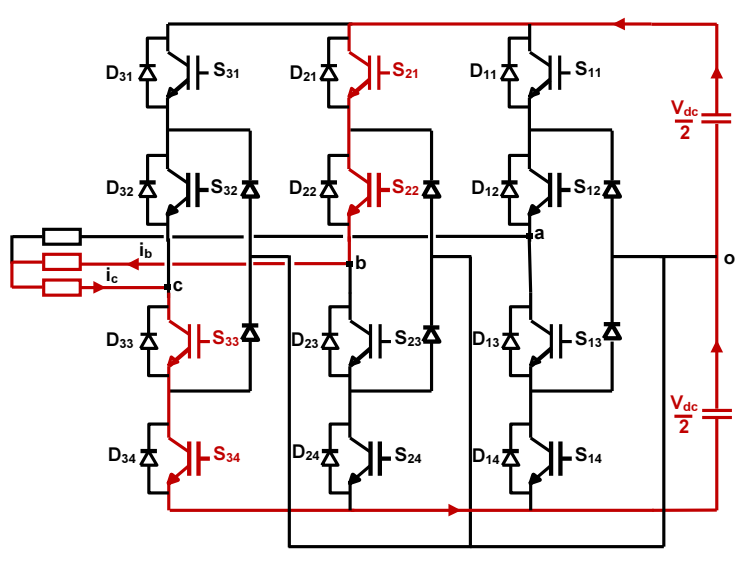

(a)

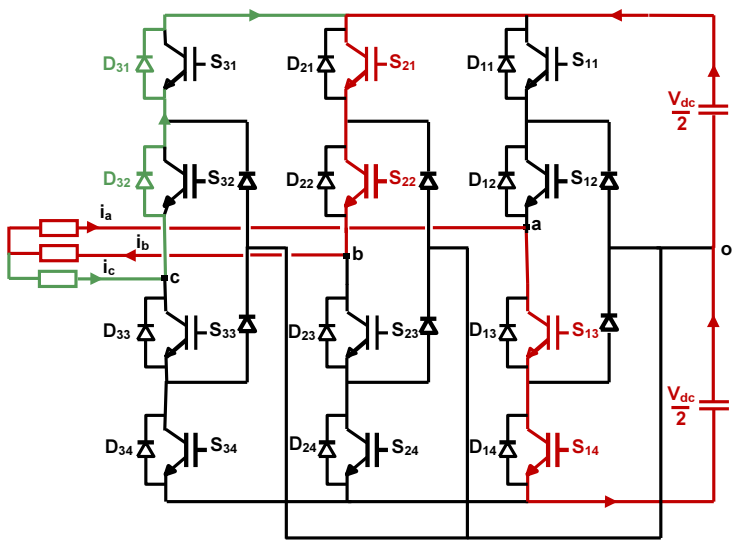

(b)

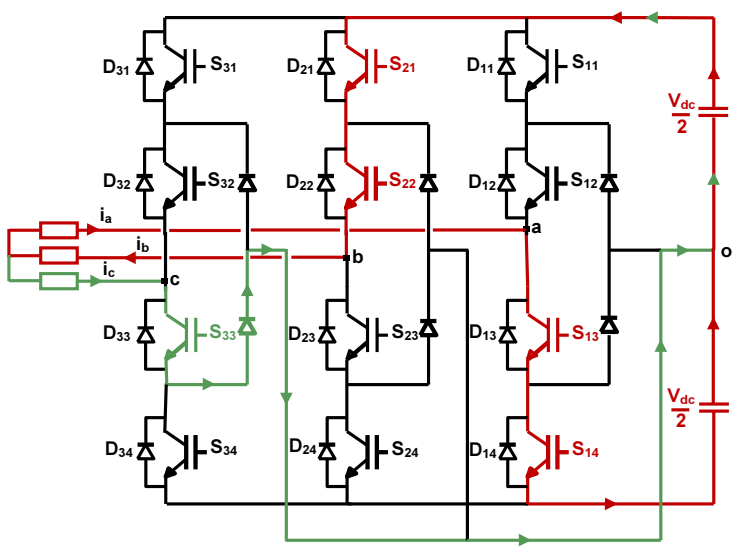

(c)

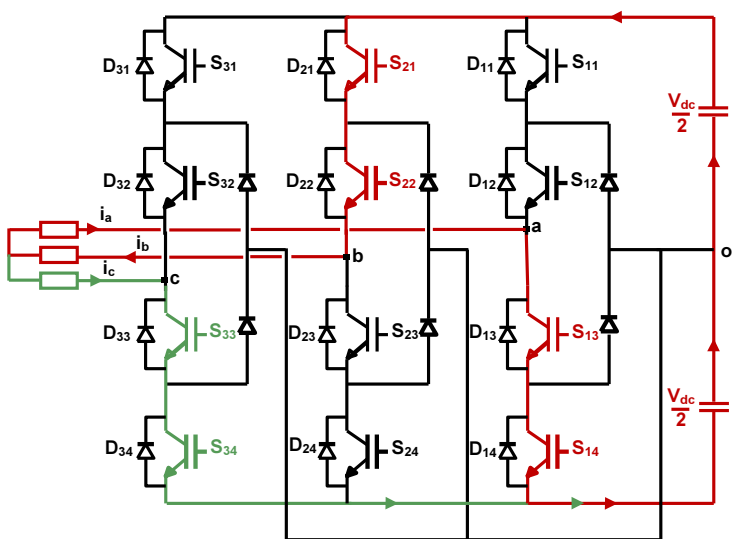

(d)

Figure 8: Current flowing during: Legend (a): sector I, (b): commutation under DTC-2 scheme, (c): commutation under DTC-3 scheme $\left(\Omega^{*} \leq \Omega_{\text {limit }}\right)$ and $(\mathrm{d})$ : commutation under DTC-3 scheme $\left(\Omega^{*}>\Omega_{\text {limit }}\right)$. 
Table 7: The vector selection table of the DTC-3 strategy.

\begin{tabular}{|c|c|c|c|c|c|}
\hline$c_{\tau}$ & +1 & -1 & $c_{\tau}$ & \multicolumn{2}{|c|}{+2} \\
\cline { 5 - 6 } & & & $\Omega^{*} \leq \Omega_{\text {limit }}$ & $\Omega_{\text {limit }}$ \\
\hline \hline Sector I & $\mathbf{V}_{8}(000011000011)$ & $\mathbf{V}_{2}(000000000011)$ & Sector VI $\rightarrow$ Sector I & $\mathbf{U}_{2}(010011000011)$ & $\mathbf{U}_{8}(110011000011)$ \\
\hline Sector II & $\mathbf{V}_{9}(001111000000)$ & $\mathbf{V}_{3}(000011000000)$ & Sector I $\rightarrow$ Sector II & $\mathbf{U}_{3}(001111000010)$ & $\mathbf{U}_{9}(001111000011)$ \\
\hline Sector III & $\mathbf{V}_{10}(001100000011)$ & $\mathbf{V}_{4}(001100000000)$ & Sector II $\rightarrow$ Sector III & $\mathbf{U}_{4}(001101000011)$ & $\mathbf{U}_{10}(001111001100)$ \\
\hline Sector IV & $\mathbf{V}_{11}(000000111100)$ & $\mathbf{V}_{5}(000000001100)$ & Sector III $\rightarrow$ Sector IV & $\mathbf{U}_{5}(001000111100)$ & $\mathbf{U}_{11}(001100111100)$ \\
\hline Sector V & $\mathbf{V}_{12}(110000110000)$ & $\mathbf{V}_{6}(000000110000)$ & Sector IV $\rightarrow$ Sector V & $\mathbf{U}_{6}(110000110100)$ & $\mathbf{U}_{12}(110000111100)$ \\
\hline Sector VI & $\mathbf{V}_{7}(110000000011)$ & $\mathbf{V}_{1}(110000000000)$ & Sector V $\rightarrow$ Sector VI & $\mathbf{U}_{1}(110000100011)$ & $\mathbf{U}_{7}(110000110011)$ \\
\hline
\end{tabular}

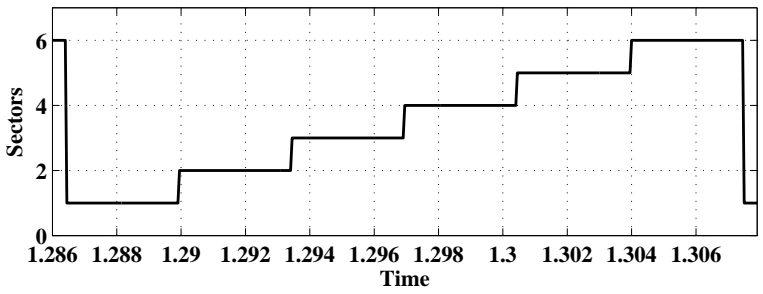

(a1)

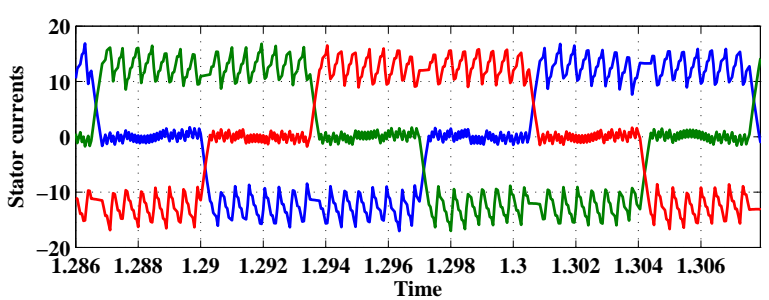

(b1)

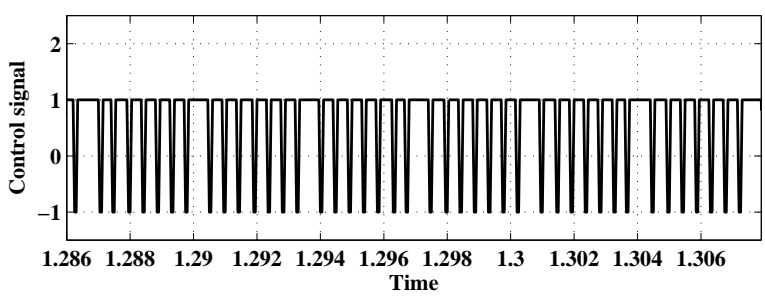

(c1)

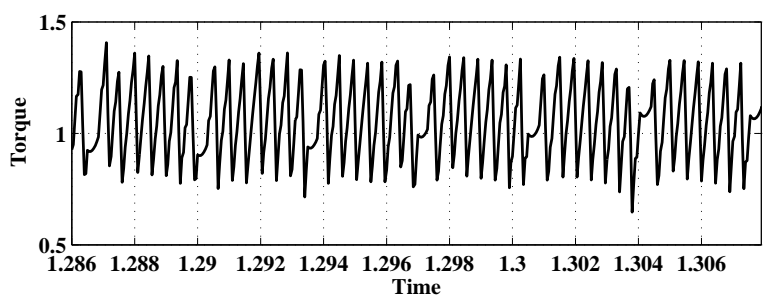

(d1)

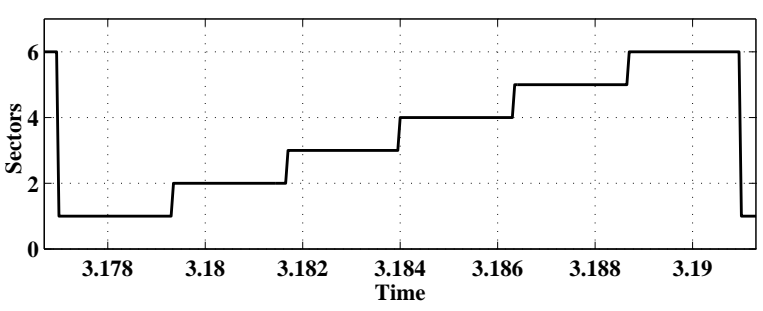

(a2)

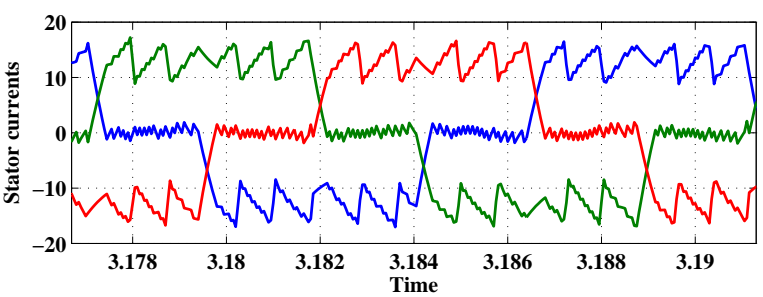

(b2)

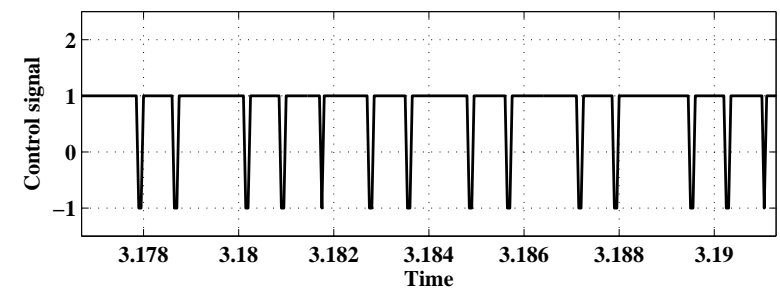

(c2)

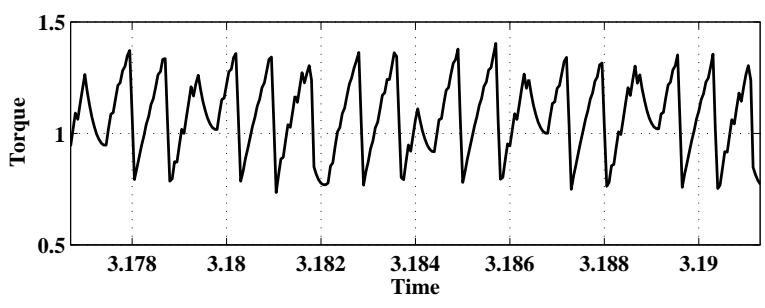

$(\mathrm{d} 2)$

Figure 9: Simulated steady-state variables provided by the classic DTC-1 scheme at $\Omega=+100 \mathrm{rad} / \mathrm{s}$ (subscript "1") and $\Omega=+150 \mathrm{rad} / \mathrm{s}$ (subscript "2"). Legend (a): sector succession, (b): stator currents, (c): control signal $\mathrm{c}_{\tau}$ and (d): electromagnetic torque. 


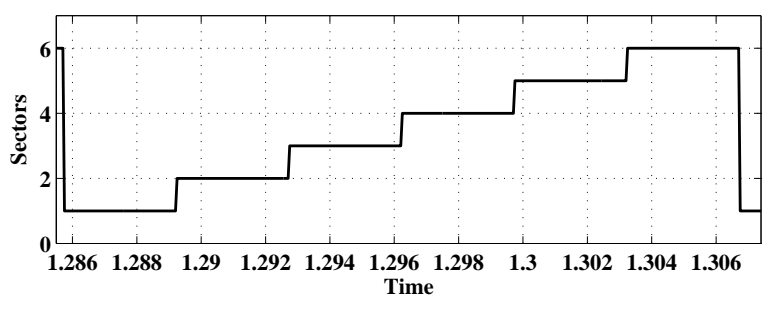

(a1)

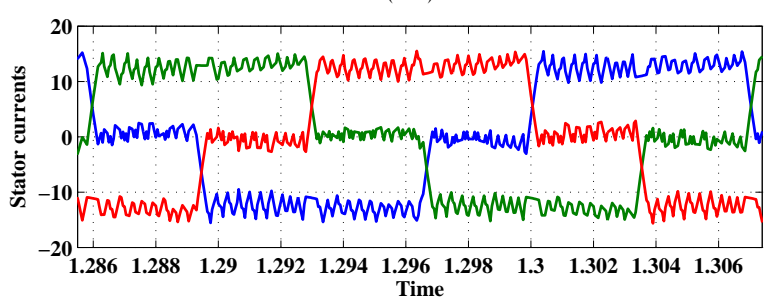

(b1)

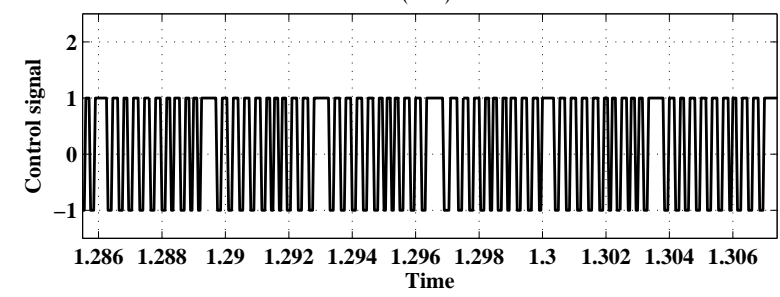

(c1)

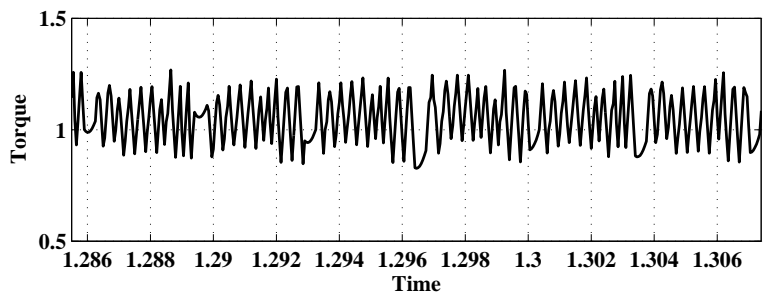

Figure 10: Simulated steady-state variables offered by the DTC-2(subscript "1") and the proposed DTC-3

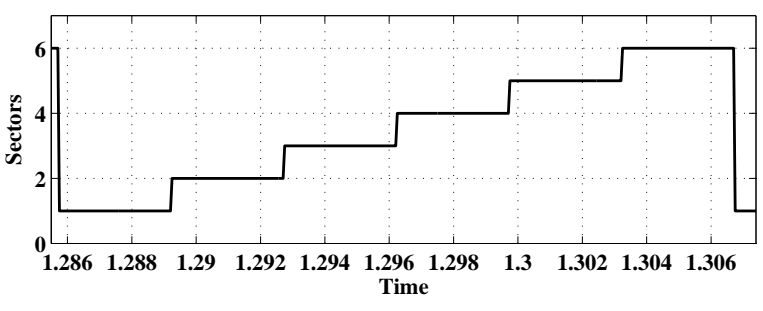

(a2)

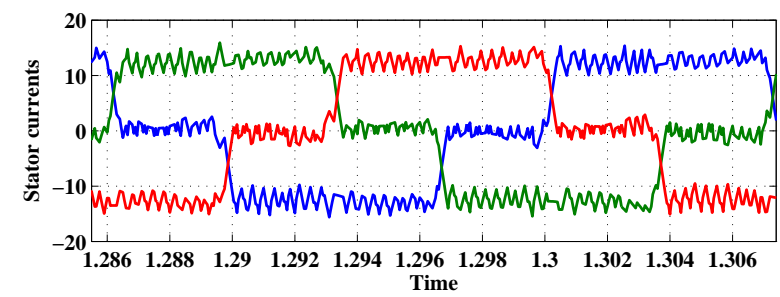

(b2)

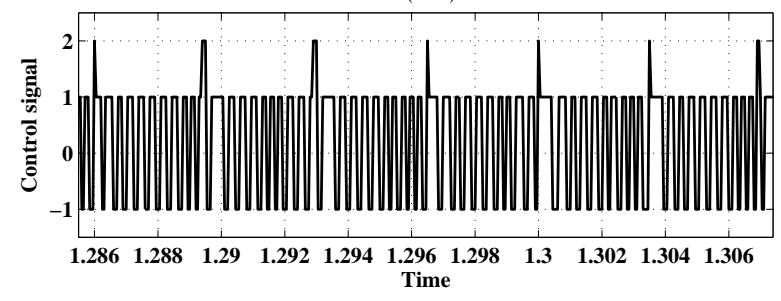

(c2)

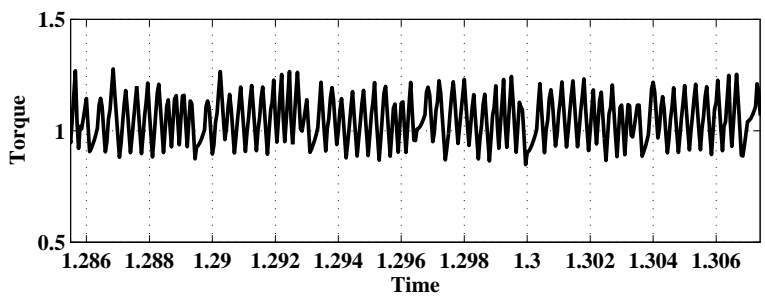

Figure 10: Simulated steady-state variables offered by the DTC-2(subscript "1") and the proposed DTC-3 (subscript "2") schemes at $\Omega=+100 \mathrm{rad} / \mathrm{s}$. Legend (a): sector succession, (b): stator currents, (c): control signal $\mathrm{c}_{\tau}$ and $(\mathrm{d})$ : electromagnetic torque.

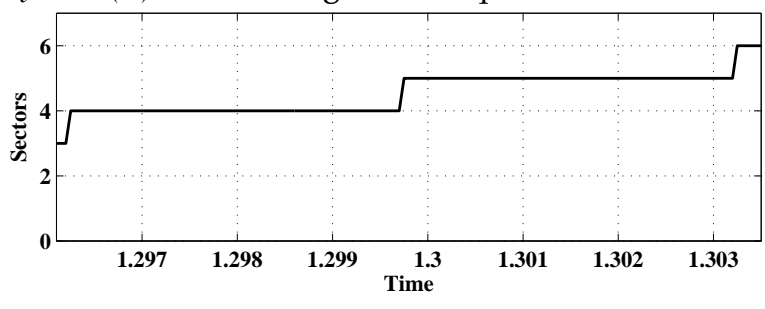

(a1)

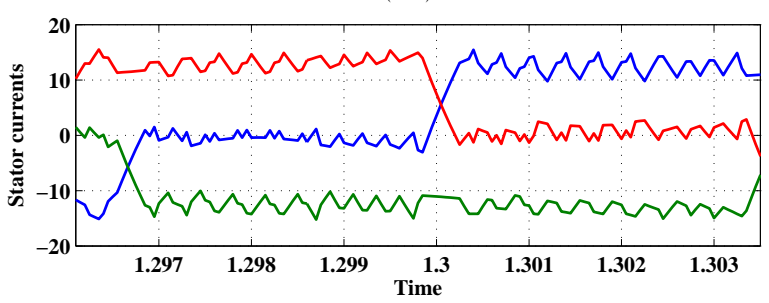

(b1)

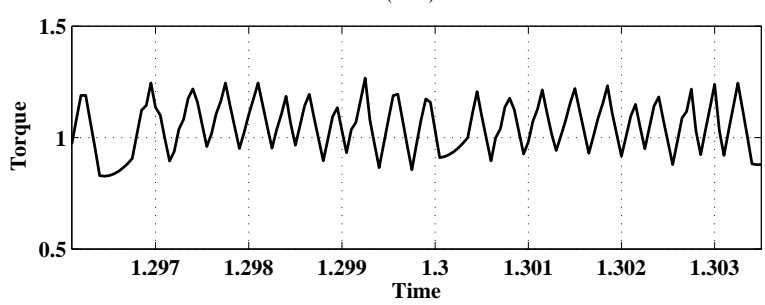

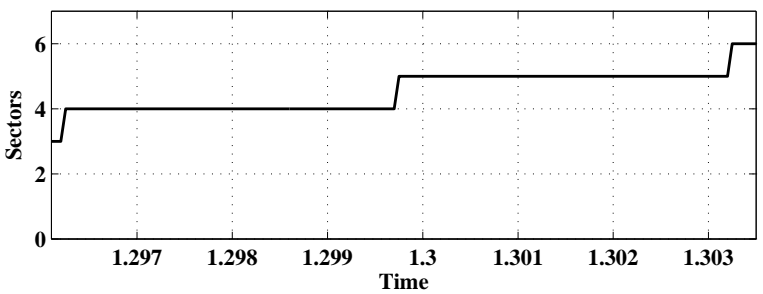

(a2)

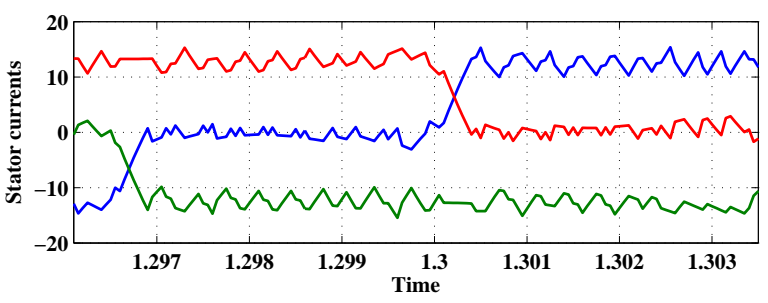

(b2)

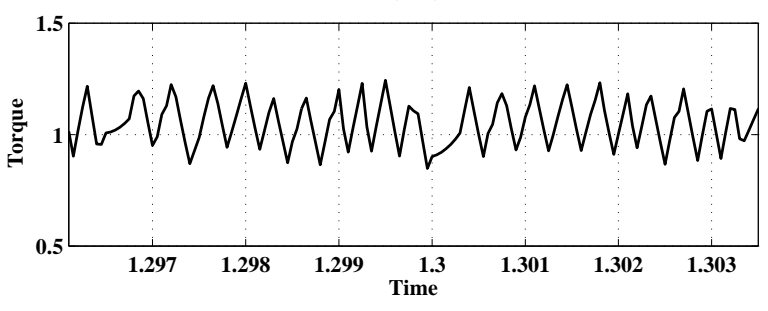

(c1)

(c2)

Figure 11: Simulated steady-state variables offered by the DTC-2 scheme (subscript "1")and DTC-3 (subscript "2") strategies for a speed $\Omega=+100 \mathrm{rad} / \mathrm{s}$. Legend (a): commutation from sector IV to sector V, (b): the stator currents zoom, and (c): the electromagnetic torque zoom. 


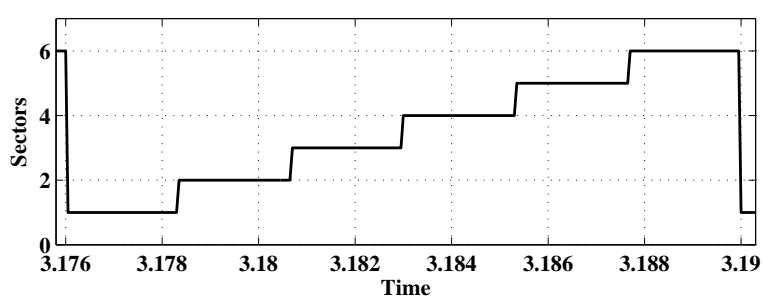

(a1)

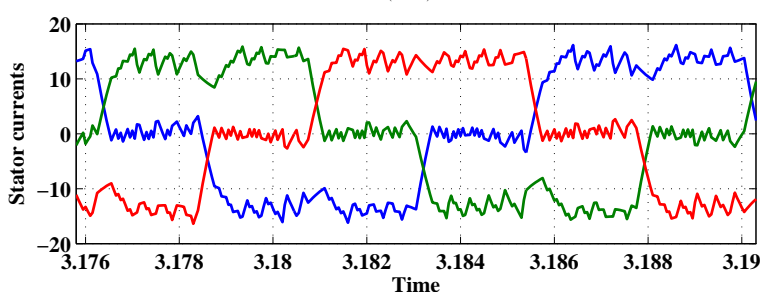

(b1)

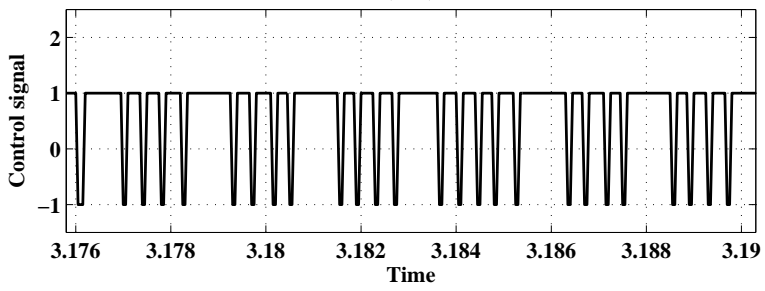

(c1)

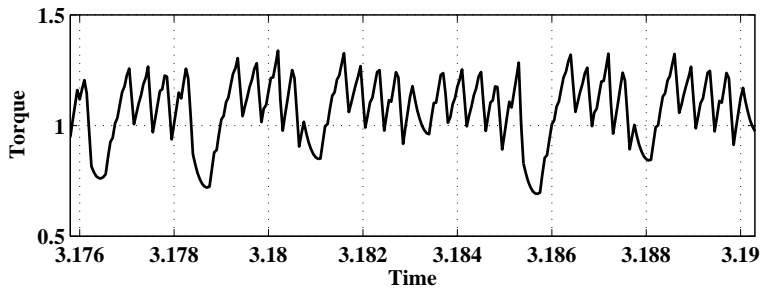

(d1)

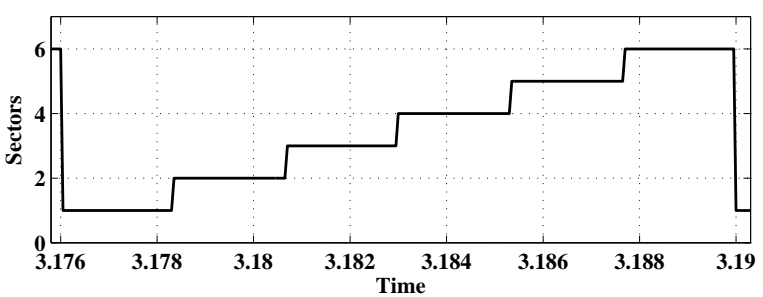

(a2)

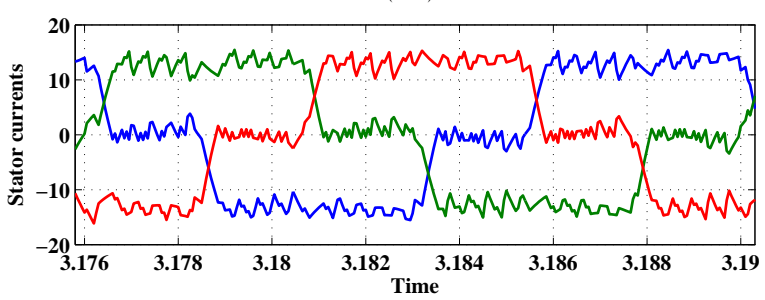

(b2)

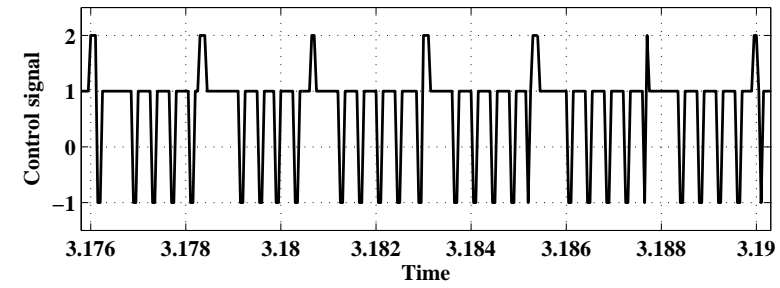

(c2)

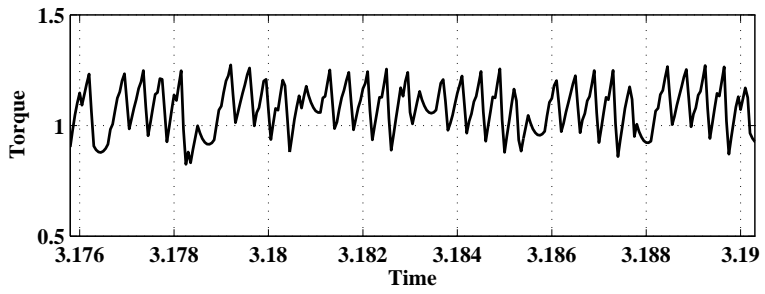

(d2)

Figure 12: Simulated steady-state variables yielded by the DTC-2 (subscript "1") and the proposed DTC-3 strategies at $\Omega=+150 \mathrm{rad} / \mathrm{s}$. Legend (a): sector succession, (b): stator currents, (c): control signal $c_{\tau}$ and (d): electromagnetic torque.

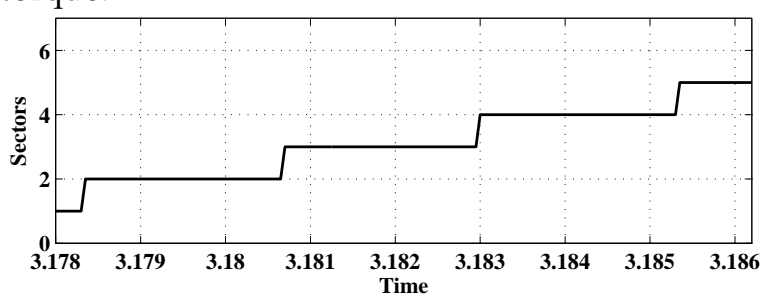

(a1)

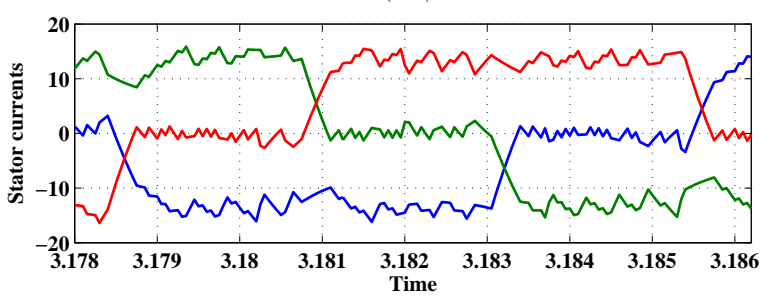

(b1)

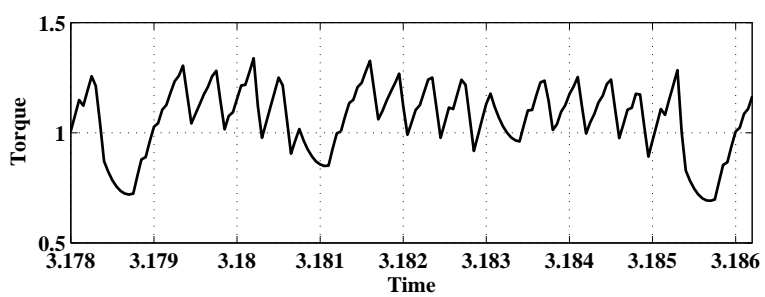

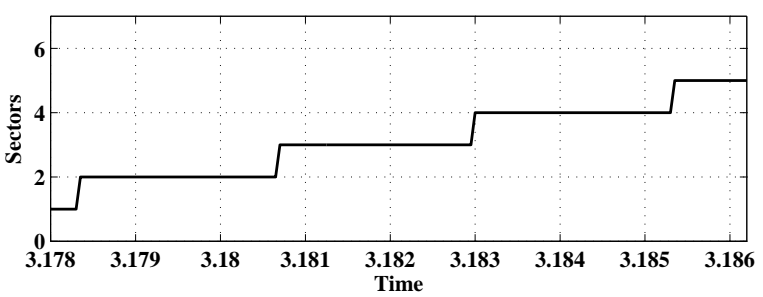

(a2)

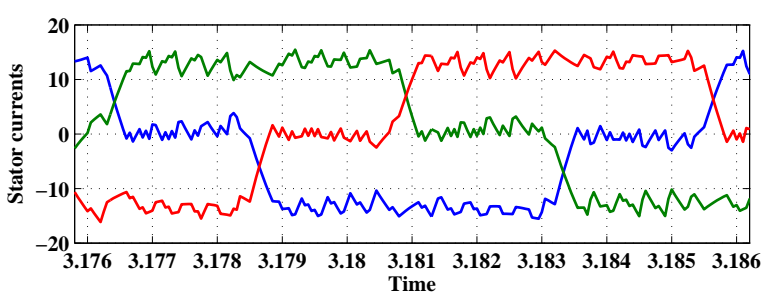

(b2)

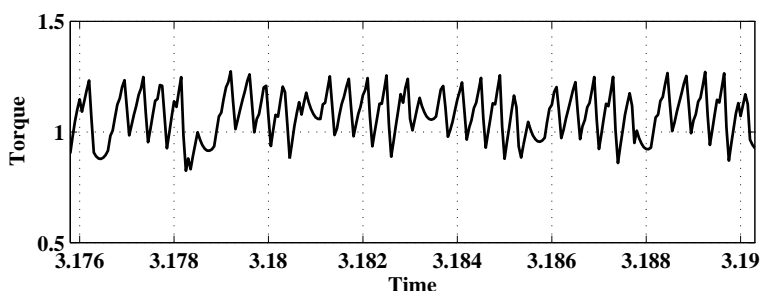

Figure 13: Simulated steady-state variables yielded by the DTC-2 strategy (subscript 1) and the proposed DTC-3 one for a speed $\Omega=+150 \mathrm{rad} / \mathrm{s}$. Legend (a): commutations from sector II to sector IV, (b): the stator currents zoom, and (c): the electromagnetic torque zoom .

www.astesj.com 


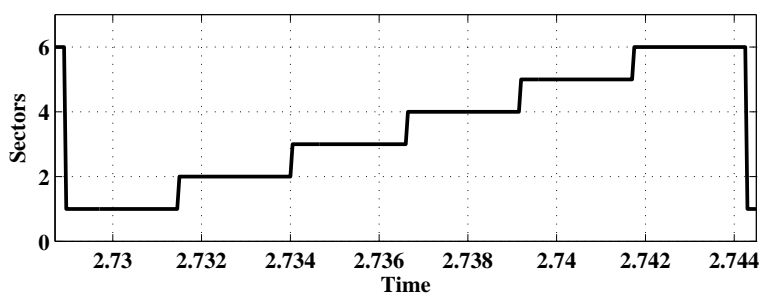

(a1)

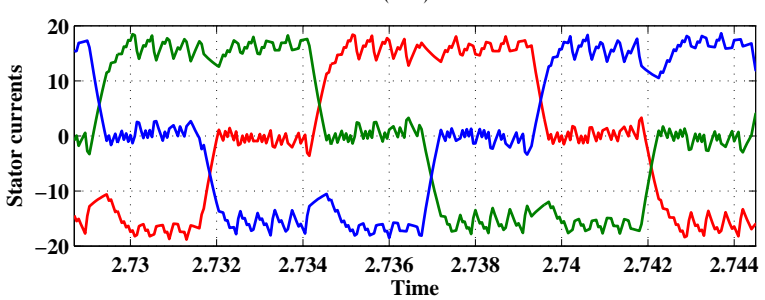

(b1)

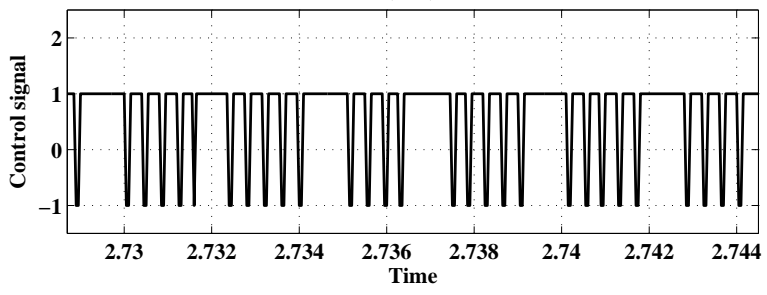

(c1)

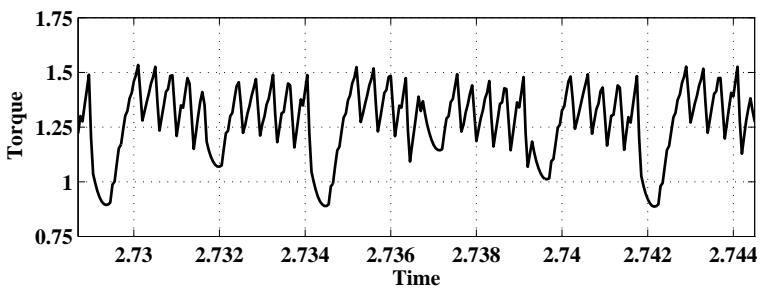

(d1)

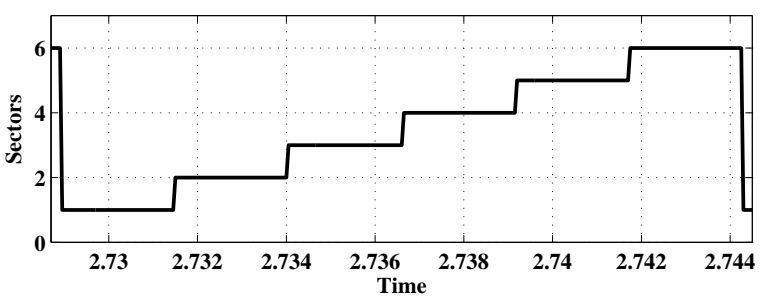

(a2)

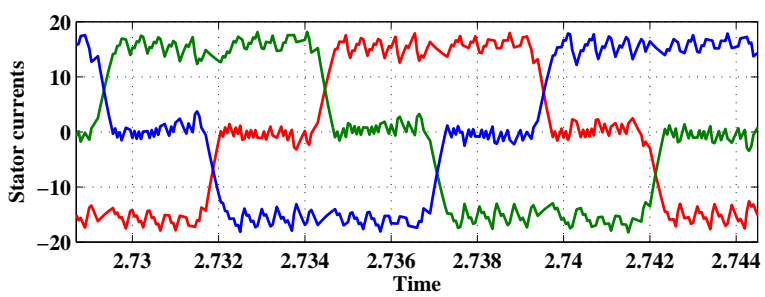

(b2)

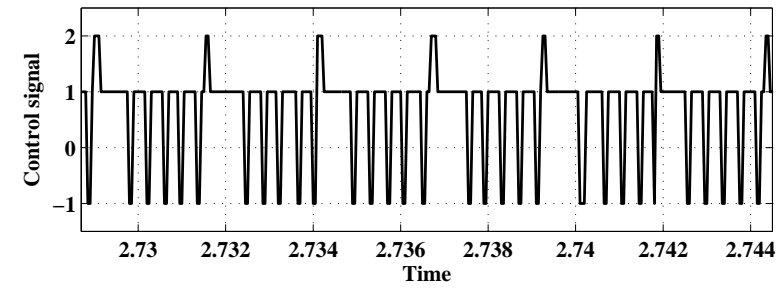

(c2)

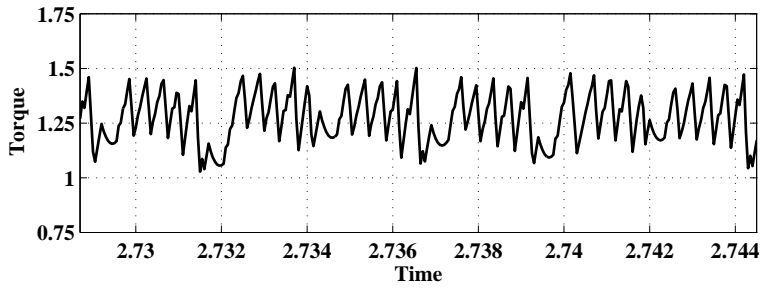

(d2)

Figure 14: Simulated transient-state variables offered by the DTC-2(subscript "1") and the proposed DTC-3 schemes. Legend (a): sector succession, (b): stator currents, (c): control signal $c_{\tau}$ and (d): electromagnetic torque.

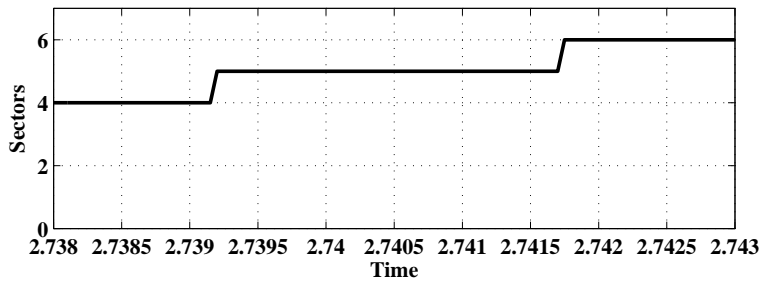

(a1)

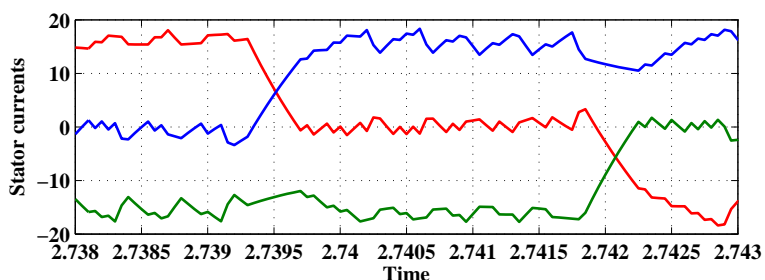

(b1)

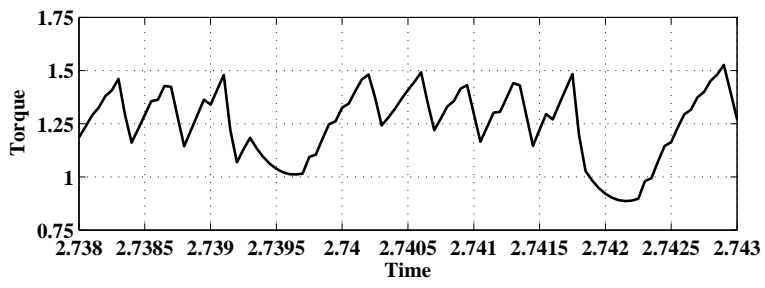

(c1)

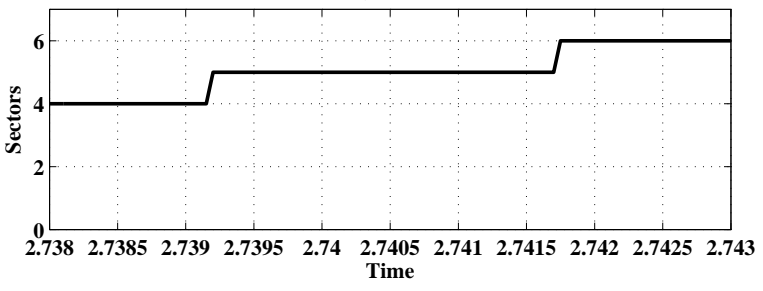

(a2)

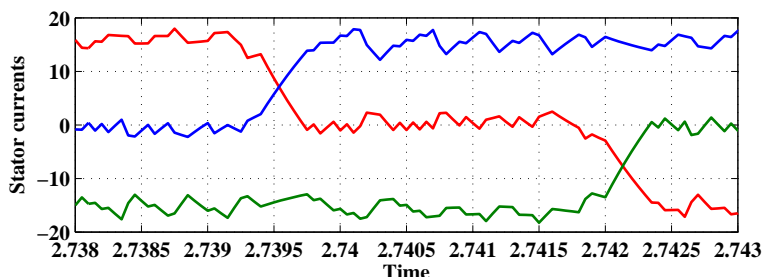

(b2)

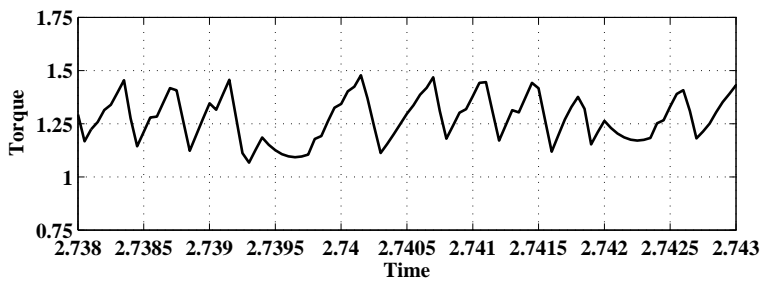

(c2)

Figure 15: Simulated transient-state variables offered by the DTC-2 strategy (subscript 1) and the proposed DTC-3 one.Legend (a): commutations from sector V to sector VI, (b): the stator currents zoom , and (c): the electromagnetic torque zoom . 


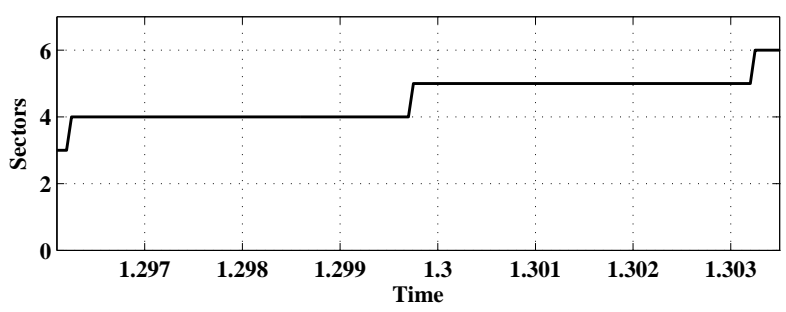

(a1)

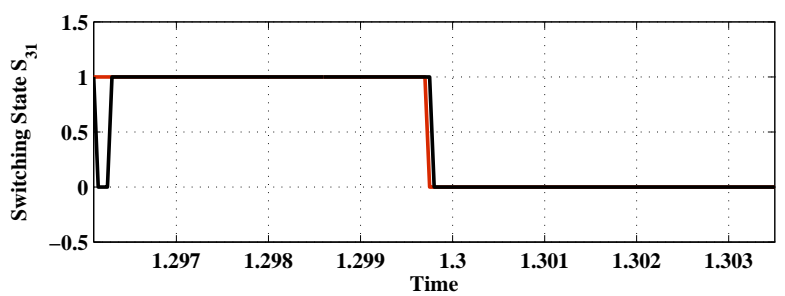

(b1)

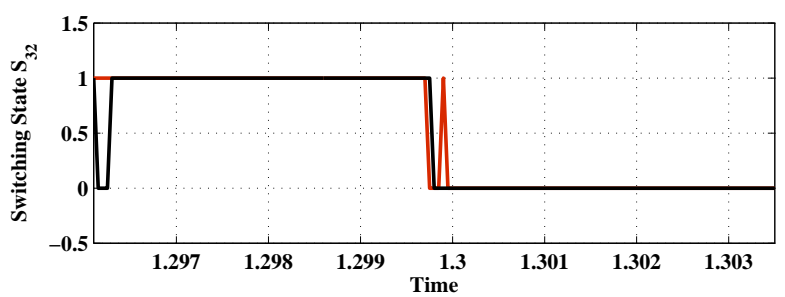

(c1)

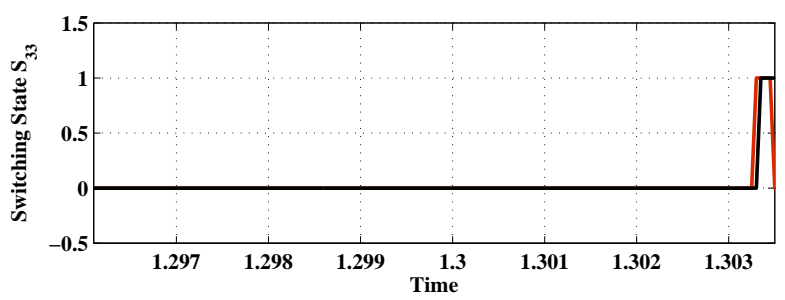

$(\mathrm{d} 1)$

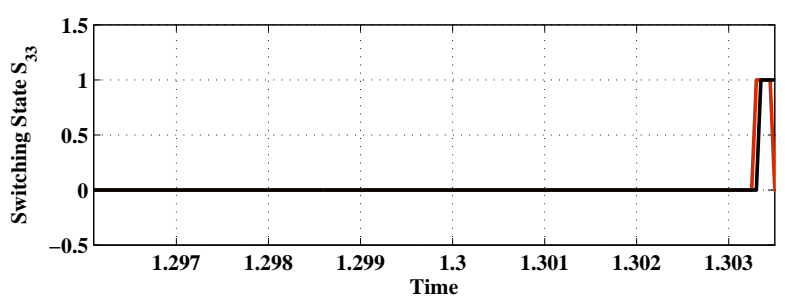

(e1)

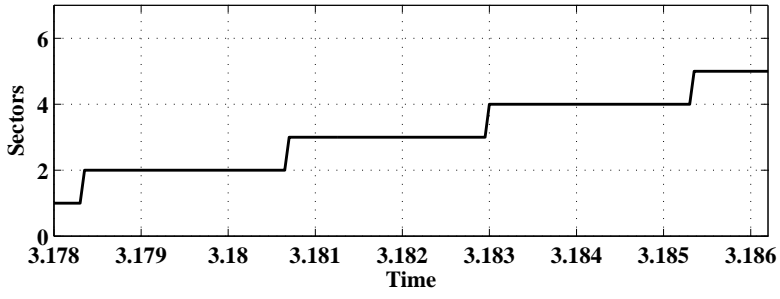

(a2)

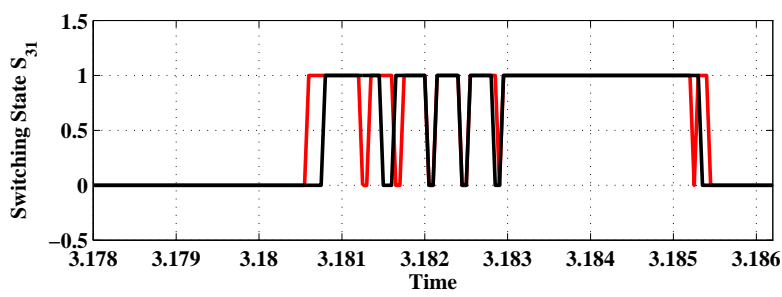

(b2)

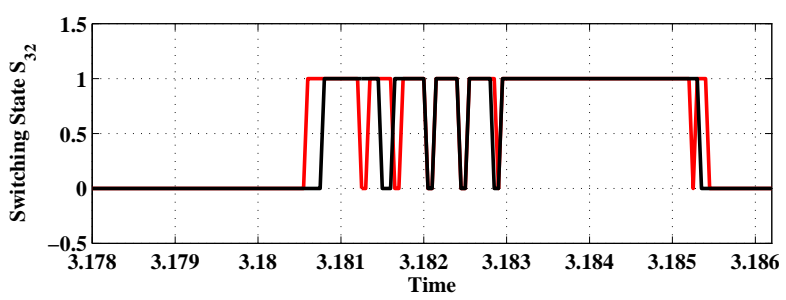

(c2)

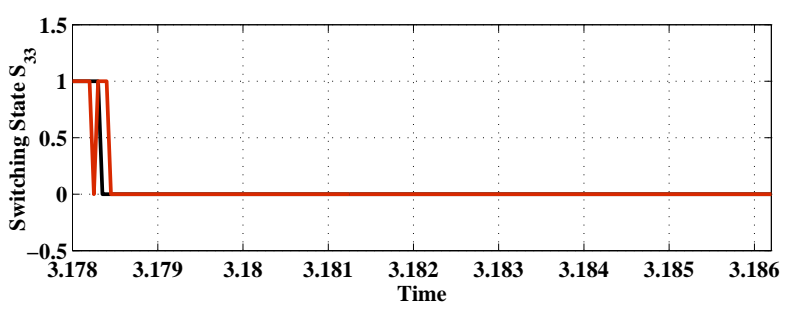

$(\mathrm{d} 2)$

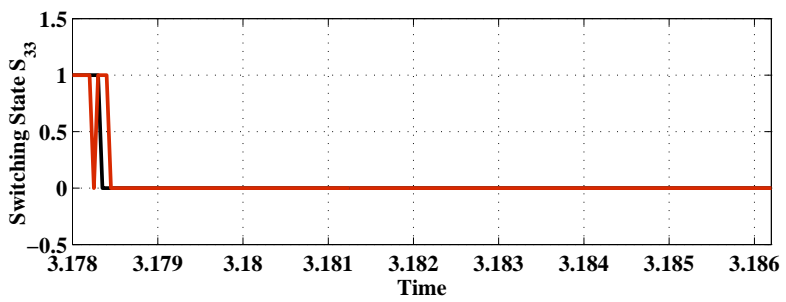

(e2)

Figure 16: Simulated steady-state variables under the DTC-2 scheme (color black) and the proposed DTC-3 one (color red) for two reference speeds $\Omega=+100 \mathrm{rad} / \mathrm{s}$ (subscript 1) and $\Omega=+150 \mathrm{rad} / \mathrm{s}$ (subscript 2). Legend (a): commutations from sector II to sector IV, (b): $S_{31},(c): S_{32},(d): S_{33}$, and (e): $S_{34}$. 
Moreover, simulation conditions characterizing the simulation study are listed below:

- a sampling period $\mathrm{T}_{s}=55 \mu \mathrm{s}$,

- a proportional gain $\mathrm{K}_{p}=1$,

- an integral gain $\mathrm{K}_{i}=0.5$,

- a load torque $=1 \mathrm{Nm}$,

- a limit speed $\Omega_{\text {limit }}=110 \mathrm{rad} / \mathrm{s}$

- the hysteresis bounds are: $\varepsilon_{\tau 1}= \pm 0.0012 \mathrm{Nm}$ and $\varepsilon_{\tau 2}= \pm 0.0036$.

To analyze the effectiveness of the proposed DTC2 and DTC-3 strategies, this section deals with a simulation-based comparison between these strategies. By using MATLAB/SIMULINK, the proposed strategies are implemented. The obtained simulations results are illustrated in Figures. 10, 11, 12, 13, 14,15 .

\subsection{Performance of the proposed strate- gies during sequence operation:}

Figures 9,10 and 12 show the waveforms of the current, the torque controller output $c_{\tau}$ and the torque waveforms at steady-state operation.

By comparing Figures.9(d), 10(d) and 12(d), one clearly notice that the DTC-1 scheme leads to an important torque dips thanks to the application of the Intermediate active voltage vectors. Both DTC-3 and DTC-2 strategies lead to a low torque dips during sequence operation thanks to the application of the Half active voltage vectors.

During sequence operation, both DTC- 2 and DTC3 schemes present almost the same torque waveforms. This is expected thanks to the application of the the same vectors. The difference concerns the torque decrease during commutations from sector to sector .

\subsection{Performance of the proposed strate- gies during commutations from sector-to-sector :}

To evaluate the proposed DTC schemes effectiveness during commutations from sector-to-sector, Figures. 11 and 13 give a zoom of the electromagnetic torque and the stator currents at steady-state operation. Figure 16 illustrates the steady-state waveforms of the switching states $S_{31}, S_{32}, S_{33}$ and $S_{34}$ with the sector succession.

As shown in Figures. 11(b1) and 13(b1), during the commutation from sector IV to sector V, the unbalancing between the current rising time and the current falling time affected the electromagnetic torque waveform. As a result of this, the DTC-2 strategy is penalized by a high torque dips. The comparison of Figures 10 (c1) and 12 (c1) confirms that commutation torque dips is more serious and more strong at high speed.
Compared to DTC-2, this commutation phenomenon is resolved for the DTC-3 strategy. Therefore, during the commutation from sector IV to sector $\mathrm{V}$ and in the case of the reference speed $\Omega^{*}=150 \mathrm{rad} / \mathrm{s}$ $\left(\Omega^{*}>\Omega_{\text {limit }}\right)$, the current $i_{c}$ is forced to flow through the IGBTS $\left(S_{31}, S_{32}\right)$ and the supply source $V_{d c}$ instead of the freewheeling diodes $\left(\mathrm{D}_{33}\right.$ and $\left.\mathrm{D}_{34}\right)$ as shown in Figures 16(b1), (b2), (b3) and (b4). However, from the analysis of Figures 16(a1), (a2), (a3) and (a4) in the case of a reference speed $\Omega^{*}=100 \mathrm{rad} / \mathrm{s}$ $\left(\Omega^{*} \leq \Omega_{\text {limit }}\right)$, it can be clearly noticed that the current $\mathrm{i}_{c}$ is forced to flow through the IGBT $S_{32}$, the clamped diode and the supply source $\frac{V_{d c}}{2}$ instead of the freewheeling diodes $\left(\mathrm{D}_{33}\right.$ and $\left.\mathrm{D}_{34}\right)$. Consequently, $\left|d i_{a} / d t\right|$ and $\left|d i_{c} / d t\right|$ are equal for both reference speeds which results a high dynamic of the torque without commutation ripple. These benefits are confirmed in Figures. 11(a2), 11(a3), 13(b2) and 13(b3).

The performance of DTC strategies under a transient-state is presented in Figures.14 and 15. Accordingly, compared to DTC-2 and DTC-1 schemes, one can evidently affirm that the developed DTC-3 scheme leads to the lower commutation torque dips for both transient and steady-state operations.

\section{Conclusion}

BLDC motor is integrated in various applications due to its different advantages. However, the BLDC motor drive has the drawback of high torque ripple which affects the performance of this system. Thus, torque ripple minimization is a crucial necessity. This paper has been focused on the development of two DTC schemes dedicated to BLDC motor drives. Simulation work has been accomplished to highlight the developed schemes effectiveness and performances. It has been found that the developed DTC-3 scheme has guaranteed the less distortion in the line currents and less commutation torque dips. This developed strategy has been based on the compensation of the difference between the slopes of the incoming and outgoing phases currents.

\section{References}

[1] J. Rodriguez, J.-S. Lai, and F. Z. "Peng, Multilevel inverters: A survey of topologies controls and applications", IEEE Trans. Ind. Electron., vol. 49, no. 4, pp. 724-738, Aug. 2002.

[2] Y. Liu, A. Q. Huang, W. Song, S. Bhattacharya, and G. Tan, "Smallsignal model-based control strategy for balancing individual dc capacitor voltages in cascade multilevel inverterbased statcom, Industrial Electronics",IEEE Transactions on, vol. 56, no. 6, pp. 22592269, 2009

[3] H. Vahedi,K. Al-Haddad, P.-A. Labbe, and S. Rahmani, "Cascaded multilevel inverter with multicarrier pwm technique and voltage balancing feature", in Industrial Electronics (ISIE), 2014 IEEE 23rd International Symposium on. IEEE, 2014, pp. 21552160

[4] J. P. Lyons, V. Vlatkovic, P. M. Espelange, A. A. M. Esser, and F. F. Want, "Five level high power motor drive converter and control system", U.S. Patent 6058 031, May 2, 2000. 
[5] S. Bernet, T. Bruckner, and P. Stiemer, Three-point converter and method for its operation, U.S. Patent 6219 265, Apr. 17, 2001.

[6] M. A. Doss, E. Premkumar, G. R. Kumar, and J. Hussain, "Harmonics and torque ripple reduction of Brushless DC Motor (BLDCM) using cascaded H-bridge multilevel inverter" , in Proc. IEEE ICPEC, Feb. 2013, pp. 296299.

[7] Chan, C. C., Jiang, J. Z., Xia, W., Chan, K. T. "Novel wide range speed control of permanent magnet brushless motor drives". IEEE transactions on power electronics, 10(5), 539546,1995

[8] T. Shi, Y. Guo, P. Song, and C. Xia, "A new approach of minimizing commutation torque ripple for brushless DC motor based on DC-DC converter", IEEE Trans. Ind. Electron., vol. 57, no. 10, pp. 3483-3490, Oct. 2010.

[9] K. Ohishi, M. Nakao, K. Ohnishi, and K. Miyachi, "Microprocessor-controlled DC motor for load-insensitive position servo system", IEEE Trans. Ind. Electron., vol. 34, no. 1, pp. 44-49, 1987.

[10] X. Huang, A. Goodman, C. Gerada, Y. Fang, and Q. Lu, "A single sided matrix converter drive for a brushless dc motor in aerospace applications", IEEE Trans. Ind. Electron., vol. 59, no. 9, pp. 3542-3552, Sep. 2012.

[11] T. M. Jahns and W. I. Soong, "Pulsating torque minimization techniques for permanent magnet AC motor drives-a re- view", IEEE Trans. Ind. Electron., vol. 43, no. 2, pp. 321-330, Apr. 1996.

[12] X. Li, C. Xia, Y. Cao, W. Chen, and T. Shi, "Commutation torque ripple reduction strategy of Z-source inverter fed brushless DC motor", IEEE Trans. Power Electron., vol. 31, no. 11, pp. 7677-7690, Nov. 2016.

[13] C. Xia, Y. Xiao, W. Chen, and T. Shi, "Torque ripple reduction in brushless DC drives based on reference current optimization using integral variable structure control", IEEE Trans. Ind. Electron., vol. 61, no. 2, pp. 738-752, Feb. 2014.

[14] G. Buja, M. Bertoluzzo, and R. K. Keshri, "Torque ripple-free operation of PM BLDC drives with petal-wave current supply", IEEE Trans. Ind. Electron., vol. 62, no. 7, pp. 4034-4043, Jul. 2015.

[15] J. Fang, H. Li, and B. Han. "Torque ripple reduction in BLDC torque motor with non-ideal back EMF", IEEE Trans. Power Electron., vol. 27, no. 11, pp. 4630-4637, Nov. 2012.

[16] W. Jiang, Y. Liao, J. Wang, P. Wang, and Y. Xie, "Improved control of BLDCM considering commutation torque ripple and commutation time in full speed range", IEEE Trans. Power Electron., vol. 33, no. 5,pp. 4249-4260, June 2018.

[17] I. Takahashi and T. Noguchi, "A new quick-response and high efficiency control strategy of an induction motor", IEEE Trans. Ind. Appl., vol. 22, no. 5, pp. 820-827, 1986. 